\title{
Offshore helicopter travel: is the UK oil and gas industry failing offshore workers?
}

DOWNIE, M., GOSLING, D. 
Offshore Helicopter Travel: Is the UK Oil and Gas Industry Failing Offshore Workers?

\begin{abstract}
UK oil and gas workers have been transported by helicopter to their workplace at offshore installations for over fifty years. During that time, there have been numerous fatal helicopter accidents. Despite calls from trade unions, families and politicians, a public inquiry has never been held into offshore helicopter transport. The authors consider whether enough has been done to ensure the safety of these workers to meet legal and ethical standards. They analyse the legal position, the implementation of recommendations made in the wake of these accidents, and the way in which the power imbalance between oil and gas companies and helicopter operators influences safety in this area. They conclude that a public inquiry is required into helicopter safety in the UK Continental Shelf area (UKCS).
\end{abstract}

Keywords: Power, legal, risk, safety, ethics.

\title{
Introduction
}

Workplace safety is a very sensitive topic involving issues of legal liability and social responsibility on the part of the employer. ${ }^{1}$ Since $1965,{ }^{2}$ helicopters have transferred workers to and from offshore oil and gas installations in the UK Continental Shelf(UKCS) across an open sea environment that is both challenging and hazardous. ${ }^{3}$ Since then, in the region of one hundred and thirty two lives have been lost as a result of helicopter accidents within the UKCS. (Appendix 1). The goal for air safety, as stated by the International Association of Oil and Gas Producers (IOGP) is "the individual risk per period of flying exposure for an individual flying on OGP contracted business should be no greater than on the average global airline." ${ }^{4}$ Global statistics indicate that "At 0.5 per million flights, the 
mortality risk for offshore helicopter occupants is 10 times higher than for jet Commercial Air Transport (CAT) passengers'3 'There is a belief, endemic within certain parts of the (oil and gas) industry, that helicopters are, by design and operating concept, less safe than fixed wing aircraft and less tolerant of flaws or error in design or operating procedure. ${ }^{5}$

The catastrophic Piper Alpha disaster on 6th July 1988 in which one hundred and sixty seven workers were killed highlighted the dangers facing offshore workers. The seminal 1990 Cullen report ${ }^{6}$ into the disaster resulted in a profound change in attitude towards all safety aspects in the UKCS with the genesis of a new safety regime emerging.

On 14th March 1992, a Super Puma helicopter shuttling workers from the Cormorant Alpha platform to a nearby accommodation vessel in rough weather, crashed into the North Sea killing eleven workers and crew. Five were trapped in the fuselage and 6 drowned after managing to egress the helicopter. A FAI was held shortly afterwards and the sheriff who conducted the inquiry made reference to a need to look at wider issues of causation that fell outside the FAI terms of reference including the influence of commercial pressures of the oil and gas industry on safety, Additionally there was a call at this time to change state legal aid entitlements so that legal representation of interested parties was available to those with limited means at future inquiries.

An AAIB report was also published in $1993,{ }^{7}$ with recommendations made to conduct a full review of helicopter safety. For the first time seakeeping performance; design and escape time; data gathering; and, training were identified in this report. Twenty six years on, these are yet to be satisfactorily implemented despite both the CAA and the AAIB revisiting the same issues serially in subsequent UKCS helicopter accident investigations. As a consequence, these four areas remain the focus of safety improvements today and indeed this research. 
Had these recommendations been acted upon at that time with the sentiment present post Cullen Report many of the deaths in subsequent helicopter accidents may have been avoided.

In the UKCS area, there were Super Puma accidents in 1997 and 2009 killing twelve and sixteen respectively and a Sikorsky accident in 2002 leaving eleven dead, nine oil workers and two crew, focussed attention on the safety of offshore transportation. On 23rd August 2013 an AS332 Super Puma helicopter with eighteen oil and gas workers and crew travelling from an offshore platform in the North Sea crashed into the sea during the approach to land at Sumburgh Airport in Shetland. Four workers died in this accident. ${ }^{8}$

Within this context, the authors examine the recommendations made since 2013 by various bodies to improve helicopter safety in the UKCS area, the extent to which these have been implemented, the factors preventing implementation and the relevant legal liabilities which apply. They consider whether enough has been done to ensure safe transportation of offshore workers in the UKCS area.

\section{Investigatory Systems}

After an aviation incident in the UK, investigations are carried out by the Civil Aviation Authority (CAA) and the Air Accident Investigation Board (AAIB). In Scotland, a Fatal Accident Inquiry (FAI) must be held into any death at work. ${ }^{9}$ Its purpose is to find the cause of the accident and make recommendations so that a similar accident does not happen again. Any evidence uncovered during the inquiry may be used in any subsequent prosecution or civil proceedings. Fatal Accident Inquiries have an important role to play in ascertaining the cause of an accident and can consider the profoundly human causes of accident outcome whereas the CAA and AAIB focus on the technical approaches. Evidence uncovered during a FAI can be useful in subsequent proceedings. There are several drawbacks of the system. Legal Aid is available for family members who qualify financially however where more than on member of a family applies for Legal Aid they must give justification for separate legal 
representation. Therefore, many family members are often reliant on trade union support. Costs can prohibit some trade unions from providing legal representation for family members. The limited scope of a FAI does not uncover wider issues or identify patterns across a series of accidents. The Crown Office and Procurator Fiscal Service have been slow to instigate FAIs for the accidents of 2009 and 2013 accidents. ${ }^{10}$ The FAI into the 2009 Super Puma accident did not take place until five years later and at the time of writing there has still not been a FAI into the 2013 Sumburgh accident despite an AAIB (2016) report and the CAA report which stated, 'this accident was clearly 'survivable', and calls from the families, trade unions, and politicians. ${ }^{11}$ It is anticipated that the FAI investigation into the Sumburgh accident will not commence until December 2019, six years after the accident.

The FAI system was modernised in 2014 but the failure to introduce a statutory timescale for the commencement of FAIs means that there will continue to be delays with consequent deterioration in witness evidence and continuation of stress on the pursuer. ${ }^{10}$

Even where a FAI finds that an accident was caused by poor design and pilot error a criminal prosecution is not inevitable since the burden of proof in criminal cases is higher (beyond reasonable doubt for prosecution compared to a balance of probabilities for FAI).

Wider safety reviews into helicopter safety have been conducted and amendments to regulations proposed. ${ }^{12}$ Recently MSP Alex Cunningham made a call in Parliament for a public inquiry. ${ }^{13}$ A key report was the CAA Safety Review of Public Sector Transport Helicopter in Support of the Transportation of Oil and Gas, CAP1145 (2014), which identified that between 1976 and 2012 of the thirty eight deaths which occurred due to helicopter ditching, thirty one failed to escape, with drowning as the main cause of death. Six of the seven who escaped from their helicopter perished in adverse sea conditions (sea state seven which has a wave height of six-eight meters). ${ }^{3}$ 
Despite several calls over the years from Trade Unions, bereaved families and others, the government has refused to order an independent public inquiry into helicopter transportation in the UKCS. "Public inquiries are major investigations - convened by a government minister - that can be gifted special powers to compel testimony and the release of other forms of evidence." 14 After the Sumburgh accident, the House of Commons Transport Committee debated a request for a full independent public inquiry into helicopter safety. This was supported by Frank Doran MP representing Aberdeen South, a constituency at the heart of the North Sea oil industry who said 'the Competition Commission carried out an inquiry into the (North Sea Oil and Gas Industry) in 2003 and recognised at the time that 'oil companies are much larger and commercially stronger organizations than the helicopter operators' and 'had become more determined to force down their supply costs'. ${ }^{15}$ The debate pointed out that 'the huge imbalance between the oil and gas companies and helicopter contractors should not be allowed to prejudice safety', the 'significant disparity in how helicopter companies operate' in relation to maintenance, training and culture and the need for stronger regulation. ${ }^{15}$ The committee members felt there should be a 'benchmark of best practice that is rigorously enforced' and further stated helicopter operators have previously tried to work towards the gold standard in safety, generally failing due to the fear of being undercut by an industry competitor. ${ }^{15}$ This debate ultimately called for a public inquiry.

The CAA generally has been ambivalent in relation to a public inquiry and felt its February 2014 review into helicopter safety was sufficiently comprehensive, however the strategic review requested by the House of Commons Transport Committee in its Report into Helicopter Safety in June 2014 included a remit to review the role of the CAA itself as they concluded the 'role and effectiveness of the CAA itself 'had not been fully investigated' ${ }^{16}$ They suggested that it would not be appropriate for the CAA to lead on such work ${ }^{16}$ and felt that only a public inquiry would be able to address this and 'the wider commercial culture in 
the North Sea operating environment, particularly concerning the pressures on operators and their contractual obligations to customers.' 16

This call was refused by the UK Government in October 2014 on the grounds that helicopter operators do not support the accusation that commercial pressure from their customers affects safety and there was no evidence to suggest competition for contracts impacted on their ability to recruit or train. ${ }^{17} \mathrm{~A}$ further request for an independent public inquiry was made in October 2017, this time raised in the Scottish Parliament. ${ }^{18}$ In March 2019 however, after industry consultation, the Scottish Parliament rejected a call to support such an inquiry because of ongoing initiatives within the industry ${ }^{19}$ and as a consequence, an inquiry at this time would not be helpful. ${ }^{20}$ In July 2019, the RMT again called for a public inquiry after the AAIB found that tiredness among ground staff in July 2018 may have contributed to a "near miss" at Aberdeen Airport involving an Airbus 175 helicopter. ${ }^{20}$

The only public inquiry into the Oil and Gas industry was held thirty years ago after the Piper Alpha disaster on 6th July 1988 when one hundred and sixty seven people lost their lives in the North Sea accident and much of today's offshore regulatory regime is a direct legacy of Lord Cullen's report into the tragedy. ${ }^{6}$ Almost the same number of lives have been lost in the thirty years since then due to helicopter accidents and a further public inquiry is needed again.

\section{Regulation}

The European Aviation Safety Agency (EASA) plays an important role in aviation safety in the European Union. Its tasks include drafting European safety legislation which regulates operators, inspections, training and devising and implementing standardisation programmes across Member States. It manages the safety certification of aircraft engines and parts and the approval of organizes carrying out aircraft design, production and maintenance and it is also responsible for data collection, data analysis and research to improve aviation safety. 
EASA issued Rule Making Task RMT. 0120 which was created in 2005 and launched in October 2012 with the aim of taking a holistic approach to helicopter ditching, water impact and survivability, although its prime focus remains on airworthiness. ${ }^{12}$

However, the House of Commons Transport Committee concluded they were 'concerned that regulatory inertia on the part of the EASA is leading to unnecessary risk for offshore workers' ${ }^{16}$

\section{Recommendations for Improvement}

As a result of the CAA CAP1145 and AAIB (2016) safety reviews, a number of industry recommendations were proposed. These have been made by two main reports, namely the CAA CAP1145 and the AAIB (2016) report into the Sumburgh accident which led to EASA proposing amendments to their regulations.

CAP 1145, identified the following key issues, confirmed by AAIB (2016) primarily related to helicopter design:

1. The sea-keeping performance required of ditched helicopters is inadequate leading to an excessive risk of capsize post ditching.

2. The certification requirements do not address water impacts, leading to inadequate post-crash operability of emergency flotation systems.

3. The time required to escape from a flooded and usually inverted helicopter cabin will exceed the ability of at least some of the occupants to hold their breath.

4. There are no regulatory restrictions on operations over sea conditions where a reasonable prospect of safe rescue cannot be assured. ${ }^{3}$ The CAP1145 further said "it is possible that the ditching performance of current helicopters in real sea conditions will be less than that claimed."3 
Recommendations were directed at both the EASA and the CAA. These recommendations covered four areas namely seakeeping performance; design and escape time; data gathering and training.

These recommendations are fundamental to the safety of offshore workers and arguably should have been addressed sooner. Whilst some of the recommendations have been implemented, others have not.

\section{Recommendations Which Have Been Implemented}

Sea Keeping Performance. Hostile seas make it more difficult for rescues to take place. ${ }^{21}$ The main issues are the level of sea state in which helicopters fly, helicopters working beyond their certified capability and the likelihood that the certified capability is inaccurate.

UK helicopter flights can now only fly when there is a maximum sea state six except in response to an emergency and restrictions have been imposed so helicopter operations must cease where the wave height is greater than the helicopter certified ditching performance.

Helicopter Design and Escape Time. Helicopter operators have been required to ensure that the emergency flotation system (EFS) is armed for all overwater departures and arrivals ${ }^{21}$ and a new standardised clothing policy has been introduced ${ }^{22}$ to retaining core body warmth.

Passengers' ability to exit the helicopter after a crash is critical as 'if passengers cannot fit through the push-out windows, they are not only at greater risk themselves, but also increase the risk to their fellow passengers, whose access to an exit may be blocked.' ${ }^{21}$ CAA rules now require every offshore helicopter passenger to have their shoulder width measured to ensure size requirements are met before being allowed to fly. ${ }^{23}$

However 'the time required to escape from a flooded and usually inverted helicopter cabin will exceed the ability of at least some of the occupants to hold their breath'. ${ }^{3}$ Breath hold times 'are less than 20 seconds and can be as little as 6 seconds' ${ }^{3}$ At the time of the Sumburgh accident, the industry used an Emergency Breathing System (EBS) Category B 
rebreather ${ }^{3}$ which research concluded was inadequate when it was deployed at short notice or underwater. ${ }^{16}$ Passengers now travel seated next to an emergency window exit, and, Category A EBS, must be used unless the helicopter is equipped with side floats. ${ }^{16}$

Training. Training is an important part of offshore helicopter safety and helicopter operators must now regularly review all safety briefing material to ensure that it is current and consult workers to ensure material is easily understood and fit for purpose. ${ }^{16}$

As well as passenger training, it is essential that pilots are adequately trained. Since Sumburgh, significant progress has been made towards the standardisation of pilot training and adherence to helicopter operating procedures. ${ }^{21}$

These are the main actions taken. However, as the Head of a Canadian Public Inquiry into an oil and gas helicopter fatal crash stated 'let us look for a moment not at what industry says but at what it did ${ }^{31}$ in relation to improving helicopter safety.

Recommendations Made but Not Yet Implemented

Despite the progress detailed above, there are substantial and important safety recommendations which have not been implemented mainly due to cost considerations.

Sea-Keeping Performance. Crucially, research conducted advised 'the currently accepted means of demonstration of compliance the claimed sea-keeping performance of any helicopter should be treated with caution'3 and 'helicopters tested in realistic sea conditions were found to capsize in sea state 4 to $5^{3}$ suggesting helicopters are legally able to fly in conditions beyond their operational capability because performance tests are not realistic enough. If helicopters were restricted to fly at their safe operational capacity, this would have a significant impact on both oil and gas companies and helicopter operators. If helicopters were only allowed to fly up to sea state four or five, between 8.55 percent and 27.7 percent of flights, on average would be cancelled. Depending on the North Sea operating areas this 
cancellation could rise to 33.8 percent. (see Appendix 2). There is a real potential for conflict between commercial decision making and safety.

Helicopter Design. Compulsory side floating capability has not been introduced. This locates additional flotation devices high on the fuselage, providing an air pocket which prevents total inversion and keeps airspace inside the cabin. ${ }^{24}$ Whilst EBS Category A is now compulsory, this was implemented as an alternative to the introduction of side-floating capability. It does not however provide the same degree of risk mitigation as the introduction of a side-floating capability. ${ }^{8}$ The "provision of an air pocket was the only fully effective method identified to ensure post-capsize survivability" ${ }^{8}$ although it 'would present more of a challenge, both from the perspective of design and rulemaking' ${ }^{8}$

Whilst helicopters flying in the UKCS area are fitted with flotation equipment that deploys automatically on contact with water, these must be manually armed. ${ }^{3}$ Automatic arming is not mandatory despite the CAA and EASA accepting the need for this and the risks of manual operation. ${ }^{8}$

CAA Meeting minutes in September 2016 record 'PPE such as EBS should not form the first line of defence or be used to compensate for deficiencies in the basic aircraft design ${ }^{25}$ however they go on to state that another consideration was 'objections had been received from the helicopter manufacturers to the application of auto EFS arming and on the mandate of the air pocket (e.g. side-floating helicopter) scheme.' and 'in the manufacturers' view the cost/benefit isn't justified as they consider EBS to be sufficient.' ${ }^{25}$

Numerous design issues have been identified in relation to helicopters. CAP1145 identified the primary causal factor in 83 percent of the selected accidents related to helicopter design. ${ }^{5}$ This includes exit windows, exit mechanisms and life rafts. Helicopter design in relation to emergency exits concerns regulations regarding number, location and exit size based on fixed wing aircraft evacuations. These are based on land-based evacuations 
and not underwater, where issues are very different and relate to the time taken for a large number of passengers to exit. ${ }^{8}$

Minimum size limits within current requirements are only applicable to designated emergency exits and other windows are unregulated. ${ }^{8}$ If the exit is not of regulated size this will not allow successful egress. ${ }^{8}$

Anthropometric data has not been updated since the original 1984 study $^{26}$ in relation to UK offshore workers. Results from research conducted in $2017^{27}$ suggests UK offshore workers have increased in weight by an average of 19 percent. ${ }^{8}$ thus a higher percentage of workers will be less able to exit timeously thus risking lives. However rather than redesign helicopters to take account of the increased size of a modern worker, workers who are too large to fit through the emergency exits are no longer allowed to fly. ${ }^{3}$

Another example of the reluctance to commit to the redesign of helicopters can be seen in relation to emergency exits, 'one of the principal causes of death is that passengers and crew have difficulty locating the jettison mechanism and, if they do find it, they experience confusion and difficulty operating it. ${ }^{28}$ Research has also identified how the use of helicopters with different mechanisms impacts evacuation training and successful evacuation..$^{8}$

After successfully exiting the helicopter, passengers need to shelter in a life raft. There is difficulty deploying life rafts as they are biased towards upright helicopter release. ${ }^{8}$

Fortunately, in the Sumburgh accident this helicopter had been modified by a Norwegian subsidiary of the operator and had life raft handles installed for use in such a situation. Further, no instructions are provided on the underside of a UK standard North Sea helicopter to guide passengers in life raft operation in such an emergency.

Helicopter Certification. Whilst certification standards within the industry have been introduced, this can be misleading as 'not all helicopters operating in the North Sea are 
certificated to the latest standard of requirements' ${ }^{3}$ as they are mainly applicable to new designs. $^{3}$

This is difficult to identify as information in the public domain on helicopter types 'does not provide a complete picture of the certification requirements with which they were obliged to comply' 3 'due to it often being of 'commercial in confidence' nature'. ${ }^{3}$

At the time of its publication, the CAA review in 2014 showed no new helicopters had been introduced in the UKCS since 2007 with a significant number in operation from the 1990's, 1980's and even pre-1975. (Appendix 3). Consequently, a false picture of current helicopter safety standards and risk appears to be being presented.

Data Gathering. In the early days of the North Sea oil and gas and helicopter industry, fixed wing research was the starting point for development and the industry continues to use and adapt fixed wing aircraft systems, rather than bespoke empirical helicopter research. Examples of this include Flight Data Monitoring (FDM), Terrain Awareness and Warning Systems (TAWS) and helicopter design in relation to emergency exits.

FDM means the proactive and non-punitive use of digital flight data from routine operations to improve aviation safety. ${ }^{29}$ After a successful trial in 2001, a Helicopter Operations Monitoring Programme (HOMP) was to be implemented. ${ }^{3}$ Its development however was mainly left to operators ${ }^{8}$ and there was no UK or European regulatory requirement for a HFDM Programme, although some operators did have these in place, until EASA regulated for operators to establish and maintain an FDM system by $1^{\text {st }}$ January 2019 as part of its integrated management system. ${ }^{30}$

Controlled flight into terrain (CFIT) takes place when there is an unintended in-flight collision with e.g. land or water and pilots are generally unaware until it is too late. Terrain Awareness and Warning Systems (TAWS) provide alerts to ensure pilots take appropriate action to prevent CFIT and have provided major safety benefits to fixed wing aircraft for 
years. These have been adapted to create Helicopter Terrain Awareness and Warning Systems (HTAWS) having been started by the UK CAA more than ten years ago. ${ }^{31}$ Concern has been expressed due to its lack of development and the International Association of Oil and Gas Producers have made pleas for industry support. ${ }^{32}$ The EASA proposed that HTAWS would be required to be fitted to helicopters issued with airworthiness certificates after $31^{\text {st }}$ December 2018, however this does not address helicopters already be in service at that date. ${ }^{8}$ Significantly, insufficient empirical evidence has been collected. There is little evidence available to explain why some passengers are unable to exit the helicopter and drown while others survive. Regulators have relied on extrapolation from fixed wing aircraft data, historical data and assumptions, rather than generating ongoing, up to date, fit for purpose empirical evidence. It is essential if new regulations are developed to better determine helicopter design, underwater evacuation, evacuation time limits and effective personal survival equipment that design is based on accurate data. Whilst difficulties associated with this are acknowledged, it is better to carry out controlled testing and analysis, to generate greater knowledge and understanding and thus authentic certification standards rather than relying on accident investigation evidence to validate certification assumptions. ${ }^{8}$

Accident investigators have recommended ${ }^{8}$ that recorded 'images' of the cockpit environment are required to enhance data and audio recording. ${ }^{8}$ Until recently, costs have prevented this. The introduction of regulations has also been delayed by concerns that records may not be fully protected and could be used for reasons other than safety investigation. ${ }^{8}$ 'Pilots are concerned about the use of flight data for anything other than accident investigation' and 'the increasing tendency towards the criminalisation of accidents ${ }^{33}$ Training. Action is also required in relation to Offshore Survival Training for workers. Research confirms a knowledge gap between testing conditions and the real-world scenario. ${ }^{34}$ Therefore, potentially calculations overestimate survival as when faced with a real-life 
emergency training is ineffective. ${ }^{34}$ Increasing the frequency of offshore survival refresher training is also urged. Further, when the use of Cat A EBS was introduced, initially training could not take place in water due to use of compressed air and could only be conducted as 'dry' poolside or classroom training. The introduction of 'wet' Cat A EBS training has now taken place although water depth must not be more than $0.7 \mathrm{~m} .{ }^{35}$

\section{Further improvements proposed by EASA}

A proposed RMT.0120 amendment recommended that, in order to improve the floatability of ditched helicopters, automatic arming/disarming and deployment of Emergency Floatation Systems (EFS) should be introduced; there should be provision for a rotorcraft to float and enhanced integrity and operability of life rafts. Proposed enhancements related to improved exit included a minimum size for a ditching emergency exit; exit marking and lighting for all ditching emergency exits; the optimisation of ditching emergency exits for use; one pair of ditching emergency exits for every four passengers; location of seat rows relative to ditching emergency exits to best facilitate escape and the introduction of handhold(s) adjacent to ditching emergency exits;

The amendment also required the collection of realistic data to demonstrate feasibility for occupants to easily egress the rotorcraft and enter the life raft(s) and improved availability of Emergency Locator Transmitters. ${ }^{12}$

It is likely that the proposed amendments relating to EASA RMT.0120 will not now happen until sometime in 2019 or later, Timing of implementation of this amendment is crucial, as assuming the UK withdraws from the European Union in 2019, EASA will no longer have jurisdiction over UK aviation matters. In that case the UK Civil Aviation Authority will no longer need to ensure compliance by UK-based companies with the EU aviation safety legislation." ${ }^{36}$ unless it is adopted by the UK legislature, thus further delaying its implementation. 


\section{Lessons from Norway}

To provide industry context, another perspective on safe helicopter travel is the Norwegian sector's approach to offshore helicopter travel. The UK's offshore helicopter industry is often compared unfavourably with this. The available statistics indicate that Norway's safety record over the past decade has improved, while that of the UK has declined.

During the period 1992 to 2012, Appendix 2 compares UK occurrence data with equivalent data for Norwegian offshore helicopter operations. Whilst the small number of accidents makes it difficult to draw definitive conclusions, it appears Norway's approach to health and safety is superior to that of the UK. It is acknowledged the UK flies more helicopters than Norway but between 1992 and 2012 the UK had six fatal accidents whilst Norway had one, equating to 0.34 fatal accidents per one hundred thousand flying hours for UK helicopters and 0.11 fatal accidents per one hundred thousand flying hours for Norway. Although Norway did experience a helicopter crash in 2016 where thirteen people died, those accident rates may appear to indicate a difference in safety performance. ${ }^{16}$

The Unite Trade Union and Rail, Marine and Transport Workers Trade Union (RMT) however attribute Norway's safety record to its regulatory regime, comparing Norway's introduction of 'gold' standards' in 2000 with the UK's minimum standards. The RMT stated 'if the gold standard of inspection had been in place in the UK sector, we believe four out of the five incidents since February 2009 potentially could have been avoided' which resulted in twenty fatalities. The definition of 'gold standards' in offshore helicopter safety however lacks clarity although the introduction of the Work Environment Act 2000 in Norway is seen as a factor.

Cultural factors differ in the UK and Norway, with the UK examining helicopter accidents in isolation rather than in context. Norwegians would not view helicopter accidents as individual failures but as the result of wider factors in the context of physical, environmental 
and economic pressures the pilots would be faced with. ${ }^{16}$ They also have different reporting cultures. A reportable occurrence is defined as "any incident which endangers or which, if not corrected, would endanger an aircraft, its occupants or any other person." 3 In 1976, the UK pioneered mandatory occurrence reporting (MOR) to the CAA, this directive was introduced in Norway in 2007. ${ }^{3}$ The number of reported occurrences in Norway rapidly increased after 2008 reaching a level far higher than that in the UK despite the Norwegian helicopter numbers being lower. ${ }^{3}$ The reason is not well understood although it is suggested this could be because the reporting system is newer with a more active reporting culture rather than a greater occurrence rate. ${ }^{3}$

Additionally, unlike rebuffed requests for a public inquiry in the UK, after a helicopter crash in Norway which led to fatalities in 2009, a public inquiry into helicopter transport safety was announced one month after the crash. ${ }^{1}$

A joint review was requested to understand why more occurrences are reported in Norway. ${ }^{16}$ allowing the UK to learn from the Norwegian approach particularly in relation to reporting and cultural factors. That review has never taken place.

\section{Legal Liability}

Helicopter accidents in the UKCS have been attributed to five main causes namely manufacturing defects; poor design; lack of maintenance; pilot error and Act of God. The first four causes can be reduced, and UK Health and Safety law is designed to promote good practice by imposing duties on parties who are in a position to influence the safety of others. In the case of helicopter travel within the UKCS this includes the manufacturer of the helicopter, the operator and the employer.

The Health and Safety at Work Act 1974 applies to offshore operations within twelve miles of the coast and to operations within the UKCS. ${ }^{37}$ Helicopter manufacturers have duties under section six of the 1974 Act to ensure, so far as is reasonably practicable, helicopters 
and safety equipment are designed and constructed so it will be safe and without risks to health at all times when it is being set, used, cleaned or maintained by a person at work. Their duty includes the duty to test the article and the duty to provide up to date information and instructions about its use.

Section three provides that helicopter operators have a duty to conduct their undertaking in such a way as to ensure, so far as is reasonably practicable, persons not in their employment who may be affected are not exposed to risks to their health or safety. Operators also have a duty under section four as controllers of work premises (which includes aircraft) to take such measures as it is reasonable for a person in their position to take to ensure, so far as is reasonably practicable, that the premises, all means of access thereto or egress therefrom and any plant or substance in the premises or provided for use there, is or are safe and without risks to health.

Under section two of the 1974 Act employers have a duty to ensure, so far as is reasonably practicable, the health, safety and welfare at work of all employees including, the provision and maintenance of safe plant and systems of work; and the provision of such information, instruction, training and safe place of work and safe working environment.

A breach of the 1974 Act can result in an organisation being prosecuted in criminal courts and receiving a fine of up to twenty thousand pounds and if senior managers are found to be the decision makers in a breach they can be held personally accountable under this statute ${ }^{38}$ and fined or be imprisoned for a maximum of six months.

The Offshore Installations (Safety Case) Regulations 2005 and the Offshore Installations (Offshore Safety Directive) (Safety Case etc.) Regulations 2015 ensure each UKCS installation has its own safety case identifying all major hazards (MAH's) and measures in place to control them. This includes helicopter activity within the installation's 500 metre exclusion zone which means all aspects of helicopter safety are contained within the 
operators' policies and procedures. A breach of these regulations can result in criminal prosecution and a fine or imprisonment.

If a person dies as a result of a gross breach of a relevant duty of care (including those under the 1974 Act and those discussed below) owed by an organization to the deceased and the way in which its activities are managed or organized by its senior management is a substantial element in the breach, the organization may be prosecuted in the High Court for corporate manslaughter or homicide ${ }^{\text {under }}$ the Corporate Manslaughter and Corporate Homicide Act 2007. This statute will apply where that death occurred within the seaward limits of the territorial sea adjacent to the United Kingdom and to deaths occurring on a British controlled aircraft or no longer on that aircraft as a result of wrecking or other mishap of such an aircraft. If found guilty, the organization can face extremely high fines ${ }^{39}$ The court can also make an order publicising the breach and order remedial action to be taken.

In theory, the criminal law therefore provides an incentive to manufacturers, operators and employers to take reasonable care for the safety of offshore workers however the state decides whether or not to prosecute (in Scotland the procurator fiscal). There is no accountability for the decision whether or not to prosecute and there have been no prosecutions resulting from any of these helicopter accidents. This is partly due to the standard of the burden of proof in criminal cases. Cases must be proved "beyond reasonable doubt" and this has been used as the justification for deciding not to prosecute in such cases. If prosecution is unlikely, this diminishes the deterrent effect of the criminal legislation.

Manufacturers, operators and employers also have civil legal responsibilities in relation to such accidents. These responsibilities differ in scope and degree and this difference can lead to self-employed workers being disadvantaged. Accountability under the civil law relies on individual claimants pursuing complex, lengthy and costly actions in the civil courts. 
The manufacturer has a duty of care which is owed to anyone likely to be affected by the manufacturer's negligence and that would include any passenger on the helicopter. ${ }^{40}$ However finding the evidence to prove a manufacturing defect and to prove that that defect caused the accident and injury suffered requires expert knowledge and is extremely difficult for an individual claimant to uncover particularly where there has been no prior FAI.

The helicopter operator has liability in respect of death or injury to passengers due to accidents (defined as an unusual or unexpected event that is external to the passenger). This is governed by the Montreal Convention $1999^{41}$ which imposes strict liability (i.e. no need to prove fault) on the operator for the first 113100 Special Drawing Rights (SDR). SDR are an international monetary investment asset. They can be used as a mechanism of calculating a settlement of international claims. This sum is equivalent to approximately one hundred and eighteen thousand pounds unless the operator can prove the passenger was negligent and thereby contributed to the death or bodily injury. ${ }^{42}$ Above that limit the operator will not be liable if they can prove either the damage was not due to their negligence, wrongful act or omission or that of their servants or agents ${ }^{3}$ or the damage was solely due to the negligence, wrongful act or omission of a third party. ${ }^{42}$ The claim must be made within two years of the arrival at destination. There is no upper limit to damages for injury or death however damages for psychological injuries will only be recoverable if they are caused by a bodily injury or result in a bodily injury. ${ }^{43}$ Although these provisions are the exclusive cause of action against the operator, they do not preclude action against others such as manufacturers of defective parts or employers.

If a worker is employed either by an oil company or by a subcontractor then as well as the right to sue the operator described above, they may well have recourse against that employer. Aircrew employed either by operators will be owed an employer's duty by that operator. 
Often liability is resolved by contractual arrangements between oil companies and contractors.

Some workers flying offshore are self-employed. Therefore, the non-delegable employer's duty of care described below does not apply to them.

Employers have a common law duty to take reasonable care for the safety of their employees which comprises the duty to provide a safe place of work including safe plant and equipment, a safe system of work and provision of safe colleagues. ${ }^{44}$ An employer bears strict liability for defective equipment i.e. the helicopter (or helicopter part) ${ }^{45}$ and therefore there would be no need for an employee to make a claim against the manufacturer or to prove that the manufacturer was negligent. Claims can be made within three years of date of the injury and there is no cap on damages which may include damages for psychiatric injury.

Whilst the duty does not cover the normal commute to work ${ }^{46}$ it does extend to any journey which an employee undertakes whilst in the scope of his or her work ${ }^{46}$ and covers the situation where an employee is sent abroad to work and must travel while he or she is there. ${ }^{47}$

The duty includes the need to consider suitable transport arrangements ${ }^{45}$ and the whole of the travel arrangements fall within the scope of the employer's duty of care including safety advice given to employees. ${ }^{48}$

Applying these principles to the journey offshore, it can be seen this falls within the scope of the employer's duty of care. The employer has control over the time and means of the journey, the advice and training given and selection of the operator. A safe system of work will include safe means of travel to an offshore installation (including safety procedures in the event of an emergency), a safe design of helicopter will be part of the duty to provide safe plant and equipment under the civil duty and, if exit from a helicopter in an emergency is hindered by helicopter design then that duty will have been breached. 
What is reasonable will depend on the facts and circumstances of each case including the state of knowledge in the industry and alternatives available. Factors which influence the standard of care required will include the vulnerability of the employee, (for example, younger, less experienced employees require a higher standard of care), ${ }^{49}$ riskiness of the activity i.e. the probability of injury, ${ }^{50}$ seriousness of injury ${ }^{47}$ and practicality and cost of precautions. ${ }^{51,52}$

As we have seen, helicopter flights in the North Sea are risky due to the inclement weather, sea conditions and difficulty of rescue in the event of a crash. There has been some suggestion the employer is under a non-delegable duty to carry out a risk assessment in such cases, but a failure to carry out a risk assessment would only result in liability if a properly carried out risk assessment would have resulted in a decision or precaution being taken which would have resulted in avoidance of the injury to the employee..$^{53}$ The relevant question is therefore whether if the employer had carried out a risk assessment into that particular flight would they still have sent the employee on it?

Two cases, which occurred outside the UKCS, nevertheless have implications for UKCS employers since the principles apply to all situations where employees are required to fly in the course of their employment in risky environments where aircraft are flying on the cusp of their operation limits and the accidents are attributed to pilot error.

In Dusek v StormHarbour Securities $L L P^{54}$ an employee was killed when a helicopter chartered from operators engaged through his employer's agents crashed in the Andes. His dependents sued the employers for breach of their duty of care.

The court held that the employer was therefore under a duty "to take reasonable care to see that he was reasonably safe while travelling to and from and at his place of work abroad where he was required to go in the course of his employment" and furthermore that was a duty the employer owed personally which could not be delegated to the operator or client. ${ }^{54}$ 
Although in most cases that duty did not require anything to be done, in this case, the duty was breached because the flight was high risk and the helicopter was flying close to its operational limits. $^{54}$

In this situation, employer was "required to make at least some form of inquiry into the safety of the trip and carry out some form of risk assessment." ${ }^{54}$ Enquiring whether the operator had an AOC was not enough because "an AOC does not indicate the quality of the application of the regulations in the country in question nor to its applicability to the particular charter proposed. It does not guarantee their compliance with statutory requirements or the "safe conduct of the particular flight by the operator or aircraft commander" 54

The employer should have consulted an aviation assessor who would have carried out a desk-based review at minimal cost and advised against the trip. If the employer remained minded to send the employee on the trip they should have then instructed a remote audit in the form of a questionnaire to be issued to the organization arranging the trip, consideration of key documents and follow up telephone calls. The employer was found liable in damages for the employee's death.

The limits to employer's responsibility and contrast with the liability of the organization who arranges the travel and operator were considered in the subsequent case of Cassley $\mathrm{v}$ GMP Securities Europe. ${ }^{55}$ In that case an employee died in a helicopter crash when a helicopter chartered by his employer's clients crashed in the Congolese Jungle due to pilot error. His employer admitted owing a duty of care but claimed they were entitled to rely on the client who made the arrangements for the trip. The client in turn admitted a duty of care but claimed they were not liable because they had selected a suitable operator.

The court held the operator owed a duty of care and was vicariously liable for negligence of their employees. The client also owed a duty of care which would be satisfied by selecting 
a reputable operator but importantly the court pointed out that the employer's duty of care was more onerous than that owed by their client because it was non-delegable. Therefore employers cannot avoid liability by contractual arrangement and by letting someone else arrange travel or by selecting a reputable operator, although they could have a contractual arrangement which indemnifies them in the event of liability. In Cassley there was no causative link between breach of duty and employee's death since any enquiries which should have been carried out would have revealed that this was a relatively low risk flight and the operator was a reputable carrier. Accordingly, the employers were not liable.

In the case of helicopter flights in the North Sea, the above case law leads us to conclude the UK employer has a non-delegable duty to enquire into the detail of travel arrangements and to carry out a risk assessment. The nature of North Sea helicopter transfers is more dangerous than the average fixed wing aircraft flight operated by a reputable airline. The questions to be considered in determining the employer's liability in the case of accidents in the North Sea are firstly, did the employer enquire as to the travel arrangements? Secondly, did the employer carry out a risk assessment? Finally, if the employer had done these things would a reasonable employer have sent the employee on the trip?

If the answer to all three questions is no then the employer will be liable in the event of an accident.

It can be seen that those who are employed have some advantages over those who are selfemployed. They have a choice of defendants. They can sue the manufacturer, operator or the employer. There are several situations where this might be an advantage e.g. where the accident is caused by a defective part or defective helicopter, they are out with the time limit for raising a claim against the operator, where the operator is impecunious, where there is a claim for psychiatric damages, where amount claimed is over the limit to which strict liability applies and the operator's defence under Article 21(1) (a) or 211 (b) of the Montreal 
Convention 1999 is likely to succeed, and where they want to establish jurisdiction in another state.

Although there are civil remedies available, these are retrospective and the cost of taking action is extremely high and civil legal aid is means tested and therefore not always available. Scotland does not recognise punitive damages and compensation recovered will be for any loss suffered. In most cases the claim is settled out of court and it is difficult to see what impact such actions have.

Proactive measures available to workers are extremely limited. Individual workers are protected from detriment or dismissal if they raise health and safety concerns ${ }^{56}$ However in practice there is a concern that they will be blacklisted (not required back).

The North Sea Oil and Gas industry is not heavily unionised. Health and safety law makes provision for mandatory publication of Health and Safety policies and election of Health and Safety Representatives. These representatives should be consulted and are protected from suffering detriment and dismissal ${ }^{57}$ for undertaking that role and expressing views however, unlike in Norway, they have no means of enforcing their views. ${ }^{58-60}$

Trade Unions are entitled to be consulted on health and safety matters ${ }^{61}$ but again have no statutory means of enforcing their views.

\section{Influencing Factors}

There are several factors which have influenced the current situation within the offshore oil and gas industry.

The House of Commons debate ${ }^{15}$ attributed considerable responsibility to balance of power held by oil and gas companies and subsequent pressures they exert. Although the extent to which this affects safety standards is fiercely contested, the CAA review found that all helicopter operators agreed the customer influence was too extensive, with the prevalence of contracts awarded on lowest cost basis within a short timescale, reducing an operator's 
ability to recruit and train for new contracts and challenge standards in pursuit of a successful bid. ${ }^{3}$ Additionally BALPA believes oil and gas companies enforce cost-cutting by including termination clauses in contracts allowing them to withdraw contracts if another operator can undercut price, again potentially affecting standards. ${ }^{16}$

The influential Wood Review in December 2018 identified supply chain collaboration as a fundamental behaviour in securing the successful future of the UKCS. ${ }^{62}$ Surveys conducted as part of this review revealed numerous examples of adversarial behaviours such as described above. The review goes on to say a change in cultural attitudes is needed as many relationships are power based and further states that the workforce needs to be allowed and encouraged to collaborate also. ${ }^{62}$

Further, as a result of different contractual provisions, there is a lack of Standard Operating Procedures (SOPs) and standardisation which the CAA felt could affect operators' ability to operate effectively in line with safety priorities. ${ }^{3}$

The dynamics of safety and risk perception is as a contested area. ${ }^{1}$ Recognition of the importance of power within the workplace enables explanations of different perceptions of risk ${ }^{1}$ between management and employees. There is a persistent perceptual gap ${ }^{1}$ between the two sides in its definition, seriousness and remediation.' ${ }^{1}$ with 'different realities ${ }^{6}$. Managers believe safety is better than employees, ${ }^{1}$ however despite the risk perception of the workforce seen as historically biased towards lower safety levels ${ }^{1}$ 'risk perceptions of workers and union were largely consistent with inquiry experts' ${ }^{\prime}$ Further there is a 'strong societal culture working towards union and worker legitimacy in decision making' ${ }^{1}$ with recognition 'cost cutting adversely affecting worker participation and remediation of hazards'

${ }^{1}$ As we have mentioned above, UK Health and Safety law does little to give workers an effective voice since they only have the right to be consulted and make representation. In some countries including Norway, safety delegates have unilateral power to stop work they 
deem dangerous without legal liability and they have power to influence management and achieve change ${ }^{1}$, 'a right not available to offshore workers in the UK.' ${ }^{1}$ This lack of legal protection provides more power to employers.

For the past thirty years, UK Regulatory authorities have conducted studies and provided recommendations to address known safety issues in offshore helicopter transportation, however 'few, if any, have resulted in regulations to alter design or operational standards. Delays occurred as responsibility for design and operations regulation was transferred from the UK CAA to Joint Aviation Authority (JAA), and then to EASA, however the thirty year timeframe is difficult to justify. ${ }^{8}$ There are serious concerns transferring more authority to European level is 'averaging down standards' 16 and 'regulatory inertia on the part of EASA is leading to unnecessary risk for offshore workers'. ${ }^{16}$ With the UK voting to leave the European Union, this raises further questions about which regulatory body will be responsible for civil aviation safety and creates the potential for further delays.

Industry and corporate culture have a strong influence. Today's oil and gas companies work within a complex set of legal and ethical norms and expectations ${ }^{63}$ with profitability a key measure of success. The pursuit of profit should be balanced with delivering value and fulfilling responsibilities to all stakeholders. This includes the 'duty of care' owed to employees. ${ }^{64}$ At times however, interests of different stakeholders can conflict, organizations face differing pressures and can be influenced by the most important stakeholders or tangible, short term financial results.

Whilst leaders and employees would not knowingly put workers lives at risks, corporate culture and leadership style plays a critical role in the priority duty of care is given. Corporate culture described as "the "glue" that holds organizations together' ${ }^{65}$ is dynamic and shaped by leadership behaviour. ${ }^{66}$ Leaders communicate values, beliefs and priorities based on what they place their attention ${ }^{66}$ and shape behaviours and empower employees to align with 
these. Further a leader's reaction to a crisis, such as an offshore incident, brings out the organization's core values as reactions become visible either reinforcing existing culture or changing it. ${ }^{66}$

Where corporate culture is misaligned, this can create toxic environments and create substantial risk. ${ }^{64}$ Evidence given to the House of Commons Transport Committee stated 'the EBS issue was evidence of complacency' and 'the industry has a culture of evading responsibility for mistakes'. ${ }^{16}$ In addition, despite the dangers, there was evidence of a culture of 'macho bullying that exists with the tacit acceptance of the employers' in the industry. Workers who voiced concerns were told to put on "big-boy pants or leave". 16 This aligns with objections to the release and analysis of data in relation to the Sumburgh accident for fear of its use.

'Societies look to oil and gas companies to self-regulate: to do more to guard against risks to society than merely comply with the law, ${ }^{63}$ and conclusions were reached by the Transport Committee that 'operations managers must prioritise safety, which means facilitating a culture of approachability and openness at all levels' ${ }^{16}$

The Government may also be reticent to act against such a powerful UK industry. There is potential for a conflict of interest, impacting the level of Government intervention with the consequence that the Government may be failing to protect workers. The search for renewable energy is escalating. In addition to escalating costs and politics associated with petroleum energy, substantial research and investment is required to eliminate fossil fuel. The race is on to find new sustainable alternative energy sources to reduce greenhouse gas emission which drives climate change. ${ }^{67}$ Oil and gas companies are key to alternative energy sources as many attempts to reinvent themselves to capture other energy related markets. ${ }^{68}$ The Government is therefore dependent on oil and gas companies to bring these solutions to the energy market from an environmental and economic perspective. To either criticize or 
overregulate the industry may impact success rates or lead to companies relocating to other countries. Consequently, there may be a tendency for the Government to take a laissez fare approach to the industry, which may impact on worker protection.

\section{Conclusion}

Since the Cullen Report in 1990 and subsequent 1993 safety recommendations, the wider issues of causation with regard to helicopter safety have been identified. For twenty six years, seakeeping performance; design and escape time; data gathering; and, training as well as the influence of commercial pressures. have yet to be satisfactorily implemented despite both the CAA and the AAIB revisiting the same issues serially in subsequent UKCS helicopter accident investigations. Various inquiries have been conducted by different stakeholders with diverse perspectives, levels of power and market positions to protect. The recommendations which have resulted from these reviews have still not been fully implemented for example, helicopters are still allowed to fly in conditions beyond their operational capability due to performance testing flaws, compulsory helicopter side floating capability has not been introduced, there are unresolved design issues in relation to helicopter exit windows, exit mechanisms and life rafts, FDM and TAWS are still based on fixed wing aircrafts and not fully bespoke for helicopter flights, and Offshore Survival Training for workers is inadequate. The tendency has been to opt for quick and less costly fixes rather than putting worker safety at the forefront of design decisions.

Crucially many helicopters currently in service have been so for many years, and for a range of reasons including cost and design limitations, are exempt from some current safety standards. Therefore, some workers are flying in helicopters which do not meet current safety regulations and additionally are doing so legally. There is a natural assumption that when industry regulations are introduced these will be fully enforced, raising safety standards, however this is not the case and raises significant ethical and legal questions. 
Effective involvement and participation of workers and unions is also critical in ensuring safety enhancements. This collaboration will help with risk mitigation and safer working environments and they should have, like Norway, the right to have empowered input and participate effectively in decisions about what, if any risk, is established as safe enough. Workers' representatives should have the legal right to demand that work stop if it is not safe. New laws should be passed and implemented fully and in partnership with workers and unions allowing collaborative decision making rather than paying lip service. Ethically this is essential, after all it is their safety and lives that are at risk. Critically, however, the UKCS oil field is in decline. Collaboration at all levels, and between all stakeholders, including the contractors' workforce is essential to ensure that remaining reserves are maximised.

By its lack of investment in design, the UK offshore helicopter industry is reducing access to work offshore for larger workers. The helicopters in use are mainly pre-2007 models and 'not all helicopters operating in the North Sea are certificated to the latest standard of requirements ${ }^{3}$ Regulations such as shoulder width restrictions are being put in place to work round the lack of design updates rather than accommodate the changing anthropometric makeup of the workforce. Additionally, there has been insufficient investment in empirical data and evidence gathering to provide realistic data to explain why some passengers are unable to exit the helicopter and drown while others survive.

One of the main reasons for the lack of implementation of regulations is the significant influence oil and gas companies have which brings pressure to operators, workers along with all other stakeholders including Governments. This huge power imbalance affects the ability of Governments to intervene and helicopter operators and manufacturers to carry out improvements or implement consistent standards and processes. It also prevents workers from complaining as this impacts their careers and prevents governments from imposing effective regulation. 
The legal situation is complex and although the self-employed and employees have rights which can be enforced through the civil courts in the event of an accident, their legal position is different. The self- employed have recourse only against the manufacturer or operator whereas employees can also sue their employers where there has been a breach of the employer's duty of care. Employers cannot delegate their duty and may have to carry out risk assessments if flights can be considered high risk however contractual arrangements tend to allow oil and gas companies to avoid accountability and reduces pressure on them to support calls for change.

The threat of criminal prosecution under health and safety legislation is more likely to influence the oil and gas industry than threat of civil actions however due to the difficulty in achieving standard of proof of beyond reasonable doubt, the chance of being prosecuted as a result of these accidents is remote.

Regulations have an important role to play in UK Offshore helicopter accident prevention and have generally been ineffective. There has been a failure or delay in the implementation of key industry recommendations. Regulatory bodies have little authority and are unable to impose recommendations, with no sanctions available to them to use with companies which refuse to comply. This has been exacerbated by changes to regulatory bodies over recent years which have led to delays, and the transfer of power to EASA has further raised concerns about lowering standards within the industry.

When the UK leaves the European Union, we will no longer be subject to new EASA rules and it is possible that the very rules designed to improve the situation in the North Sea will not automatically be effective in the UK. A strong regulatory body is needed with power to impose recommendations and improve safety standards. It is important the UK Government takes the necessary steps to implement these rules and to ensure the existing health and safety legislation is enforced rigorously. 
Fundamentally, the oil and gas industry requires a cultural shift. It cannot keep evading responsibility for mistakes and allow complacency about safety at the expense of profit. Strong leaders are required who stop the bullying and blame culture and create a dynamic proactive safety culture. Lessons should be learnt from the cultural approaches Norway is taking in relation to evaluating wider factors in relation to helicopter accidents, their reporting culture and their gold standard approach to safety.

The reviews which have been carried out have continually revisited the same issues, been limited in scope, piecemeal and have not resulted in a comprehensive review of the helicopter industry. The goal set for air safety by IOGP for individuals flying on IOGP business as mentioned earlier, states the risk should be no greater than for flying with an average global airline. This goal is some distance away. As the industry has been unable to conduct a wideranging review itself, an independent public inquiry is essential.

The FAI system is slow and is not designed to review the wider issues. The House of Commons Transport Committee called for a public inquiry in 2003 and although a request was made by the Scottish Government in October in $2017^{69}$ after industry consultation, the Scottish Parliament rejected a call to support such an inquiry in March 2019. ${ }^{19}$ The UK government has a crucial role to play in ensuring change takes place. It should acquiesce to demands for a public inquiry in order to provide the transparent, unbiased strategic review the industry needs. This would bring with it the power to intervene with regulations and changes required to improve safety. It should take back control from oil and gas companies. Only then will real progress be made. The government should also show leadership and support for this necessary step change in safety by introducing robust legislation, an effective regulatory body and financial incentives for companies who work towards the changes required. 


\section{Acknowledgements}

The authors would like to thank Professor Rhona Flin, Professor of Industrial Psychology Robert Gordon University and John Karlberg, Lecturer Law Robert Gordon University for their comments and suggestions.

\section{References}

1. Hart, S. Comparing Labour and Management Risk Perceptions of Offshore Helicopter Safety: Gaps, Shifts and Work Participation. Economic and Industrial Democracy 2016; I-31, p1-21.

2. Aerossurance. CAP1145 Helicopter Water Impact Survivability Statistics - A Critique, http://www. aerossurance.com/helicopters/cap1145-survivability-stats/ (2016, accessed 15 May 2018).

3. Civil Aviation Authority. (2014) CAP1145 Safety Review of Public Sector Transport Helicopter in Support of the exploitation of oil and gas, p7-233. https://www.publicapps.caa.co.uk/docs/33/CAP\%201145\%20Offshore $\% 20$ helicopter $\% 20$ review\%20and\%20annexes\%2024214.pdf (2014, accessed 10 February 2017).

4. Clark E, Edwards C. Perry P et al. Helicopter safety in the oil and gas business. In: IADC/SPE Drilling Conference. Miami, Florida, USA, 21-23 February 2006, paper no.98672 pp6. Society of Petroleum Engineers.

5. Bye R, Johnsen S. and Lillehammer G. Addressing Differences in Safety Influencing Factors-A Comparison of Offshore and Onshore Helicopter Operations. Safety, 2018; 4, $\mathrm{p} 2$.

6. Cullen, The Hon. Lord WD. The public inquiry into the Piper Alpha disaster, http://www.hse.gov.uk/offshore/piper-alpha-public-inquiry-volume1.pdf (1990, accessed $17^{\text {th }}$ August 2017). 
7. Air Accident Investigations Branch Report 2/93 on the Accident to AS332L Super Puma, G Tigh near the Cormorant 'A' Platform, East Shetland Basin, on $14^{\text {th }}$ March 1992, https://assets.publishing.service.gov.uk/media/5422f3f8e5274a13140004a1/2-1993_GTIGH.pdf (1993, accessed 2 September 2019).

8. Air Accidents Investigation Branch Report on the accident to AS332 L2 Super Puma helicopter, G-WNSB on approach to Sumburgh Airport on 23 August 2013, p12-158. https://www.assets.publishing.service.gov.uk/media/56e7eaeaed915d0379000023/AAR_ 1-2016_G-WNSB.pdf (2016, accessed 27 March 2018).

9. Inquiries into Fatal Accidents and Sudden Deaths etc. (Scotland) Act 2016, Act of the Scottish Parliament, asp. 2, section 2(3)(b).

10. Scottish Parliament Information Centre, Inquiries into Fatal Accidents and Sudden Deaths etc. (Scotland) Bill (2016), http://www.parliament.scot/S4_Bills/Fatal\%20Accidents\%20(Scotland)\%20Bill/FAIBillS ummary1.pdf (2016, accessed 20 $0^{\text {th }}$ May 2019).

11. Ward, P. Calls for inquiry into Shetland helicopter crash that killed four oil workers to be held without any further delay. https://www.dailyrecord.co.uk/news/scottish-news/callsinquiry-shetland-helicopter-crash-11915543, (25 January 2018, accessed 25 January 2018).

12. European Aviation Safety Agency. Notice of Proposed Amendment 2016-01. Helicopter ditching and water impact occupant survivability, p7-228.

https://www.easa.europa.eu/sites/default/files/dfu/NPA\%202016-01.pdf $(2016$, accessed 4 October 2019).

13. UK Parliament, House of Commons, Hansard $6^{\text {th }}$ Feb 2019 vol. 654, col. $145 \mathrm{H}$. https:/hansard.parliament.uk/Commons/2019-02-06/debates/11A8BCF5-764E-4C6E-98C4- 
CECB383CCCCB/OffshoreHelicopterSafety?highlight=helicopters\#contribution-

1E615B5A-856C-4A81-9CBE-966443BF5EA9 (6 February 2019, accessed 4 October 2019).

14. Institute for Government. Public Inquiries,

https://www.instituteforgovernment.org.uk/explainers/public-inquiries (2018, accessed 21 May 2019).

15. UK Parliament, House of Commons Hansard Debate Helicopters (North Sea), Vol.571 2013 https://hansard.parliament.uk/commons/2013-11-

27/debates/13112746000001/Helicopters(NorthSea) (2013, accessed 21 November 2017).

16. UK Parliament, House of Commons Transport Committee, Offshore Helicopter

Safety,HC289 p4-27. (2014)

https://publications.parliament.uk/pa/cm201415/cmselect/cmtran/289/289.pdf $(2014$, accessed 1st June 2017).

17. ITV. Government reject inquiry into offshore helicopter safety, https://www.itv.com/news/tyne-tees/update/2014-10-27/government-reject-inquiry-intooffshore-helicopter-safety/ (27 October 2014, accessed $4^{\text {th }}$ September 2017).

18. Thomson, A. Scottish Government 'Reviewing' Whether to Back Helicopter Inquiry, Energy Voice, https://www.energyvoice.com/oilandgas/north-sea/180952/scottishgovernment-reviewing-whether-to-back-helicopter-inquiry/ (6 September 2018, accessed $1^{\text {st }}$ February 2019).

19. Thomson, A. Government Rejects Calls for Helicopter Enquiry, Energy Voice, https://www.energyvoice.com/oilandgas/north-sea/194203/scottish-government-rejectscalls-for-helicopter-inquiry/(7 March 2019, accessed $2^{\text {nd }}$ April 2019).

20. The Herald Scotland Online. Call for Inquiry into Offshore Helicopter Safety after 'nearmiss' https://www.heraldscotland.com/news/17772142.call-inquiry-offshore-helicoptersafety-39-near-miss-39/ (15 July 2019, accessed 6th September 2019). 
21. Civil Aviation Authority. CAP1243 Safety Review of Public Sector Transport Helicopter in Support of the exploitation of oil and gas Progress Report, p8-32, https://publicapps.caa.co.uk/docs/33/CAP1243_Offshore_Helicopter_Progress_Report.pd $\underline{f}(2015$, accessed 15th October 2017).

22. Offshore Energy Today. What to Wear Under Survival Suits When Flying Offshore, http://www.offshoreenergytoday.com/what-to-wear-under-survival-suit-when-flyingoffshore/ (2014, accessed 8 April 2017).

23. Step Change in Safety. Helicopter Passengers to be Measured by Offshore Medics, https://www.stepchangeinsafety.net/news-events/news/helicopter-passengers-bemeasured-offshore-medics (2015, accessed 11 December 2017).

24. Eurocopter. EASA.2007.C16 Study on Helicopter Ditching and Crashworthiness, p4, https://www.easa.europa.eu/sites/default/files/dfu/EASAfinalreport.pdf (2007, accessed $15^{\text {th }}$ November 2017).

25. Civil Aviation Authority. Minutes of 72nd Helicopter Safety Research Management Committee Meeting, https://www.caa.co.uk/uploadedFiles/CAA/Content/Standard_Content/Safety_initiatives and_resources/Safety_projects/Helicopter_Safety_Research_Management_Committee/72 nd\%20meeting\%20HSRMC\%20minutes-final.pdf (2016, accessed 9 October 2019).

26. Light IM and Dingwall RHM. Basic anthropometry of 419 offshore workers. Offshore Survival Centre, Robert Gordon's Institute of Technology 1985.

27. Stewart A. et al. Shape Change and Obesity Prevalence among Male UK Workers After 30 Years. New Insight from a 3D Scanning Study, American Journal of Human Biology $2017 ; 29(4)$ p3. 
28. Brooks CJ, and Bohemier AP. Helicopter Door and Window Jettison Mechanisms for Underwater Escape: Ergonomic Confusion! Aviation Space and Environmental Medicine. 1997 Sep; 68(9):844-857.

29. European Authorities Coordination Group on Flight Data Monitoring. Good Practice on the Oversight of Flight Data Monitoring Programmes, https://www.easa.europa.eu/sites/default/files/dfu/EAFDM GoodPractice FDMOversigh t_v1_Ed2017.pdf (2015 republished 2017, accessed 1st June 2018).

30. European Union Commission Regulation (EU) No 965/2012 on air operations and associated EASA Decisions Consolidated version for Easy Access Rules, p1162 https://www.easa.europa.eu/document-library/regulations/commission-regulation-eu-no9652012, (accessed 4 October 2019).

31. International Association of Oil and Gas Producers. IOGP Urges use of new Helicopter Terrain Avoidance Warning System, http://www.iogp.org/blog/2017/08/18/iogp-urgesuse-of-new-helicopter-terrain-avoidance-warning-system/ (18 August 2017, accessed 10th February 2018).

32. Hawkes S and Ballard G. International Association of Oil and Gas Producers. Letter to Members, https://32zn56499nov99m251h4e9t8-wpengine.netdna-ssl.com/wpcontent/uploads/2017/08/HTAWS-Letter-to-Members-May-2017-GB-signed.pdf (5 June 2017 accessed 12 October 2017).

33. Aerossurance. Scottish Court Orders Release of Sumburgh Helicopter CVFDR, http://www. aerossurance.com/news/court-orders-release-cvfdr/ (21 June 2015 accessed 30 October 2017).

34. Power J and Simões Ré A. Human Performance in Immersion Suits, https://www. skybrary.aero/bookshelf/books/2654.pdf (2010 accessed 30 October 2017). 
35. Offshore Petroleum Industry Training Board. Category A-EBS in BOSIET/ FOET Training Programmes.

https://www.downloads.opito.com/downloads/Standards/standards-archive/category-aebs-in-bosietfoet-training-programmes-faqs.pdf (2018 accessed 10 September 2018).

36. European Aviation Safety Agency. Brexit Negotiations UK's Withdrawal from the EU, https://www.easa.europa.eu/brexit-negotiations (2019 accessed 3rd April 2019).

37. Health and Safety at Work etc. Act 1974 (Application outside Great Britain) Order, UK Statutory Instrument, SI 2013/240.

38. Health and Safety at Work Act Etc 1974. UK Public General Acts 1974 c 37, section $37(1)$.

39. BBC News. CAV Aerospace fined $£ 600 \mathrm{~K}$ over worker Paul Bowers crush death. https://www.bbc.com/news/uk-england-cambridgeshire-33731432, (2015 accessed 4 October 2019). .

40. Donoghue v Stevenson. UK House of Lords, [1932] UKHL 100.

41. International Civil Aviation Organization. Convention for the Unification of Certain Rules for International Carriage by Air - The Montreal Convention. 1999 (ICAO doc no.4698 and EU Carrier Regulation 889/2002.

42. International Civil Aviation Organization. Convention for the Unification of Certain Rules for International Carriage by Air - The Montreal Convention. 1999, (ICAO doc no. 4698), Article 20, Article 21(2(a), Article 21(2(b).

43. King v Bristow Helicopters Ltd. England and Wales Court of Appeal, [2002]1 A.C. 628.

44. Wilsons and Clyde Coal Co v English. England and Wales Court of Appeal, [1938] A.C. 367.

45. Employer's Liability (Defective Equipment) Act 1969. UK General Acts 1967 c.37.

46. Smith v Stages, England and Wales Court of Appeal. [1989] A.C. 928, at 937. 
478. Durnford v Western Atlas International Inc. England and Wales Court of Appeal, [2003] EWCA Civ 306.

48. Palfrey v Ark Offshore Ltd. England and Wales High Court (Queens Bench Division), 2001 WLUK 699.

49. Paris v Stepney Borough Council. England and Wales Court of Appeal, [1951] A.C.367.

50. Bolton v Stone. England and Wales Court of Appeal, [1951] A.C. 850.

51. Quinn v Cameron and Roberton Ltd UK House of Lords, [1958] A.C. 9.

52. Charlton v Forrest Printing Ink Co Ltd. England and Wales Court of Appeal, 1980 IRLR331.

53. Uren v Corporate Leisure (UK) Ltd and Ministry of Defence. England and Wales Court of Appeal, [2011] EWCA Civ 66.

54. England and Wales High Court, [2015] EWHC 37 (QB).

55. England and Wales High Court, [2015] EWHC 722 (QB).

56. Public Interest Disclosure Act 1998. UK General Acts, 1998, c.23.

57. Employment Rights Act 1996. UK General Acts, 1996, c. 18.

58. Safety Representatives and Safety Committees Regulations. UK Statutory Instrument SI $1977 / 500$ (as amended).

59. Health and Safety (Consultation with Employees) Regulations. UK Statutory Instrument, SI 1996/1513 (as amended).

60. Offshore Installations (Safety Representatives and Safety Committees) Regulations 1989. UK Statutory Instrument, SI 1989/971.

61. The Information and Consultation of Employees Regulations. UK Statutory Instrument, SI 2001/3426 (ICER) and Transnational Information and Consultation of Employees Regulations. UK Statutory Instrument, SI 1999/3323 (TICER). 
62. Clark N and Farkas Mills N. A Sea of Possibilities, Transforming Supply Chain Collaboration Across the UK Continental Shelf, https://www2.deloitte.com/insights/us/en/industry/oil-and-gas/uk-continental-shelfsupply-chain-collaboration.html (11 October 2017 accessed 1st May 2019).

63. Spence D. Corporate Social Responsibility in the Oil and Gas Industry: The Importance of Reputational Risk. Chicago-Kent Law Review, 2010; 86 (1).

64. CIPD Research Report. A Duty to Care? Evidence of the Importance of Organizational Culture to Effective Governance and Leadership. CIPD 2016 p5.

65. Schneider S. National vs. Corporate Culture: Implications for Human Resource Management, http://www.citeseerx.ist.psu.edu/viewdoc/download?doi=10.1.1.464.3382\&rep=rep1\&typ $\underline{\mathrm{e}=\mathrm{pd}}(1988$, accessed 7 October 2017).

66. Boniface C. Organization Culture as Driver of Competitive Advantage, p2-7, https://www.aabri.com/manuscripts/11791.pdf (2011 accessed 7 October 2017).

67. Energy Voice. UK Greenhouse Gas Emissions Fall 3\%, https://www.energyvoice.com/other-news/195713/uk-greenhouse-gas-emissions-fall-3/ (28 March 2019 accessed 1st May 2019).

68. Crawford M. What does the Energy Transition mean for Large Oil and Gas Companies? https://www.energy-uk.org.uk/publication.html?task=file.download\&id=6230 $($ June 2017 accessed $1^{\text {st }}$ May 2019).

69. Lammey M. Transport Minister Undecided on Support for North Sea Copters Public Inquiry, https://www.energyvoice.com/oilandgas/north-sea/159375/transport-ministerundecided-support-north-sea-copters-public-inquiry/ (20 December 2017 accessed 16 June 2018). 
Offshore Helicopter Travel: Is the UK Oil and Gas Industry Failing Offshore

Workers?

\section{Appendix 1}

Fatalities and Causes in the UKCS since the Commencement of the Oil and Gas Industry $^{70}$

\begin{tabular}{|c|c|c|c|c|}
\hline Date & Fatalities & Location & Cause of accident & Helicopter type \\
\hline $21^{\text {st }}$ April 1976 & 1 & Forties Field & $\begin{array}{ll}\text { Tail } & \text { rotor } \\
\text { malfunction } & \end{array}$ & Sikorsky -58T \\
\hline $12^{\text {th }}$ March 1981 & 4 & St Fergus & $\begin{array}{l}\text { Main rotor blade } \\
\text { separated due to a } \\
\text { fatigue failure of the } \\
\text { spindle }\end{array}$ & Sikorsky -76A \\
\hline $\begin{array}{ll}12^{\text {th }} & \text { August } \\
1981 & \end{array}$ & 1 & $\begin{array}{ll}\text { East } & \text { Shetland } \\
\text { Basin } & \end{array}$ & $\begin{array}{l}\text { Lost power to the } \\
\text { main rotor gearbox, } \\
\text { going out of control } \\
\text { during the ensuing } \\
\text { autorotation }\end{array}$ & Bell 212 \\
\hline $\begin{array}{ll}13^{\text {th }} & \text { August } \\
1981 & \end{array}$ & 13 & $\begin{array}{ll}\text { Off } & \text { Norfolk } \\
\text { Coast } & \end{array}$ & $\begin{array}{l}\text { Insufficient evidence } \\
\text { to explain loss of } \\
\text { power or control }\end{array}$ & Wessex \\
\hline $\begin{array}{l}14^{\text {th }} \text { September } \\
1982\end{array}$ & 6 & $\begin{array}{ll}\text { East } & \text { Shetland } \\
\text { Basin } & \end{array}$ & $\begin{array}{l}\text { Insufficient } \\
\text { evidence, although } \\
\text { adverse weather and } \\
\text { darkness were factors }\end{array}$ & Bell 212 \\
\hline $\begin{array}{ll}10^{\text {th }} & \text { October } \\
1982 & \end{array}$ & 2 & Aberdeen Airport & $\begin{array}{l}\text { One engine suffered } \\
\text { a failure of the gas } \\
\text { generator turbine }\end{array}$ & SA330J (Puma) \\
\hline $\begin{array}{l}21^{\text {st }} \text { November } \\
1984\end{array}$ & 2 & $\begin{array}{l}\text { North East of } \\
\text { Humber }\end{array}$ & Technical error & Bell 212 \\
\hline $\begin{array}{l}6^{\text {th }} \text { November } \\
1986\end{array}$ & 45 & East of Sumburgh & $\begin{array}{l}\text { Forward } \\
\text { transmission spiral } \\
\text { bevel ring failed }\end{array}$ & Chinook \\
\hline $25^{\text {th }}$ July 1990 & 6 & Brent Spar & $\begin{array}{l}\text { Pilot allowed } \\
\text { Helicopter tail rotor } \\
\text { to contact handrail on } \\
\text { approach to land }\end{array}$ & Sikorsky S-61N \\
\hline $14^{\text {th }}$ March 1992 & 11 & Cormorant Alpha & Pilot error on take off & AS332L Super Puma \\
\hline $16^{\text {th }}$ July 2002 & 11 & $\begin{array}{ll}\text { Off } & \text { Norfolk } \\
\text { Coast } & \\
\end{array}$ & $\begin{array}{l}\text { Loss of rotor head in } \\
\text { flight }\end{array}$ & Sikorsky S-76A+ \\
\hline $\begin{array}{ll}27^{\text {th }} & \text { December } \\
2006 & \end{array}$ & 7 & Morecambe Bay & $\begin{array}{l}\text { Co-pilot loss of } \\
\text { control due to bad } \\
\text { weather }\end{array}$ & Eurocopter AS365N \\
\hline $1^{\text {st }}$ April 2009 & 16 & Off Peterhead & Mechanical failure & $\begin{array}{l}\text { AS332L Super Puma } \\
\text { Mk } 2\end{array}$ \\
\hline
\end{tabular}




\begin{tabular}{|l|l|l|l|l|}
\hline Date & Fatalities & Location & Cause of accident & Helicopter type \\
\hline $23^{\text {rd }}$ August & 4 & Off Sumburgh & $\begin{array}{l}\text { Pilot error as the } \\
\text { helicopter's flight } \\
\text { instruments were not } \\
\text { monitored } \\
\text { effectively during the } \\
\text { latter stages of the } \\
\text { non-precision } \\
\text { instrument approach. }\end{array}$ & \\
\hline $\begin{array}{l}\text { Helideck } \\
\text { Accidents }\end{array}$ & 3 & & & \\
\hline Total & $\mathbf{1 3 2}$ & & & \\
\hline
\end{tabular}

\section{Appendix 2}

Impact of Restricting Operations to Certificated Helicopter Ditching Performance ${ }^{3}$ (Annexe D p27)

\begin{tabular}{|c|c|c|c|c|}
\hline \multirow{3}{*}{ Operating Area } & \multicolumn{4}{|c|}{ Helicopter Ditching Performance (Sea State) } \\
\hline & 3 & 4 & 5 & 6 \\
\hline & \multicolumn{4}{|c|}{$\%$ Operations Lost } \\
\hline Average all areas & 61.8 & 27.7 & 8.55 & 1.4 \\
\hline $\begin{array}{l}\text { Northern North Sea / West of Shetlands } \\
\text { (avg. routes A \& B*) }\end{array}$ & 66.4 & 33.8 & 12.2 & 2.4 \\
\hline Mid North Sea (avg. routes C \& $D^{*}$ ) & 55.0 & 19.8 & 4.3 & 0.4 \\
\hline Southem North Sea (avg. routes E \& F*) & 64.0 & 29.7 & 9.2 & 1.4 \\
\hline
\end{tabular}




\section{Appendix 3}

\section{Assessment of Helicopter Types in Offshore Helicopter Operations}

The CAA in their review of industry safety in 2014 assessed helicopter types themselves where helicopters were ranked by specialist engineers in the following categories: ${ }^{3}$ (p66)

1. Types which are currently in service and which potentially have a long life, large or growing fleets, providing support for offshore operations.

2. Types which are in service which have potentially reducing fleets providing support for offshore operations.

3. Types which have or may be phased out or have smaller fleet numbers providing support for offshore operations.

4. Types which only currently operate in the Search and Rescue role or have been phased out. ${ }^{3}(\mathrm{p} 66)$

Helicopter Age in Offshore Helicopter Operations ${ }^{3}$ (p66)

\begin{tabular}{|l|l|l|l|l|}
\hline \multicolumn{2}{|c|}{ Type } & Rank & $\begin{array}{l}\text { Entry into } \\
\text { operations }\end{array}$ & $\begin{array}{l}\text { UK Fleet } \\
\text { size inc SAR } \\
\text { (Nov 13) }\end{array}$ \\
\hline a & AgustaWestland AW139 & 1 & 2005 & 16 \\
\hline b & Eurocopter EC225 LP & 1 & 2005 & 22 \\
\hline c & Sikorsky S-92 & 1 & 2005 & 26 \\
\hline d & Eurocopter AS332 L2 & 2 & 1998 & 6 \\
\hline e & Eurocopter SA365 C & 2 & $\begin{array}{l}1979 \\
(2009)\end{array}$ & \begin{tabular}{l} 
(3) \\
\hline
\end{tabular} \\
\hline f & Sikorsky S-76 C++ & 2 & 2006 & 6 \\
\hline g & Eurocopter AS332 L \& L1 & 3 & 1982 & 13 \\
\hline h & Sikorsky S-76 A ++ & 3 & 1980 & 0 \\
\hline i & Eurocopter EC155 & 3 & 2007 & 1 \\
\hline j & Sikorsky S-61 & 4 & Pre-1975 & 2 \\
\hline
\end{tabular}




\section{References}

70. Oil and Gas UK. Reportable Helicopter Accidents,

https://oilandgasuk.co.uk/wp-content/uploads/2017/07/Appendix-1_Reportable-

Helicopter-Accidents-2017.pdf (2017 accessed 19 September 2019). 